\title{
Entomological surveillance with community engagement at Chagas Platform Centers for comprehensive care in the mesothermal valleys of three regions of the endemic area of Triatoma infestans in Bolivia
}

Mirko Rojas Cortez ( $\square$ mirkorcortez@gmail.com )

Fundación CEADES

\section{Maria-Jesus Pinazo}

Instituto de Salud Global Barcelona, Hospital Clinic - Universitat de Barcelona

Jimy Pinto

Fundación CEADES Cochabamba, Centro Plataforma Chagas Cercado Cochabamba

Helmut Magne Anzoleaga

Fundación CEADES Cochabamba, Centro Plataforma Chagas Cercado Cochabamba

Yurly Escobar Caballero

Fundación CEADES Cochabamba, Centro Plataforma Chagas Cercado Cochabamba

Gloria Sandy Urioste

Fundación CEADES Cochabamba, Centro Plataforma Chagas Sacaba Cochabamba Jareth Sanchez

Fundación CEADES Cochabamba, Centro Plataforma Chagas Punata Cochabamba

Mario Castellon

Fundación CEADES Cochabamba

\section{Wilson Garcia}

Fundación CEADES Cochabamba, Centro Plataforma Chagas Sucre Chuquisaca

\section{Lourdes Ortiz Daza}

Centro Plataforma Chagas Tarija, Universidad Juan Misael Saracho Tarija

Isabel Gonzales Mur

Centro Plataforma Chagas Tarija, Universidad Juan Misael Saracho Tarija

\section{Daniel Lozano}

Fundación CEADES Cochabamba

\section{Joaquim Gascon}

Instituto de Salud Global Barcelona, Hospital Clinic, Universitat de Barcelona

Faustino Torrico

Fundación CEADES Cochabamba 
Research

Keywords: Chagas Disease, Vector Surveillance, Triatoma infestans, Triatoma sordida, Bolivia

Posted Date: December 17th, 2019

DOI: https://doi.org/10.21203/rs.2.19009/v1

License: @ (i) This work is licensed under a Creative Commons Attribution 4.0 International License. Read Full License 


\section{Abstract}

\section{Background}

The detection of residual foci inside the houses, or the reinfestation of triatomines is one of the main entomological surveillance challenges. Actions aimed at increasing the probability of vector detection and to detect re-infestation when the density of vector populations is low, is a priority objective for Chagas control programs.

\section{Methods}

Families belonging to local communities were responsible of triatomine specimens capture, following a strategic methodology based on entomological surveillance with community participation developed by the National Chagas Programme of the Ministry of Health of Bolivia. The main objective of the study is to evaluate the entomological surveillance strategy with community engagement implemented in Chagas Platform Centers for comprehensive care (CPs). The degree of intradomicillary residual vector infestation, the main seasonal period of triatomines capture, and natural infection by trypanosomatids rates were evaluated.

Results

In rural and peri-urban Punata, in the Department of Cochabamba, the houses infestation rate by triatomines exceeds the national average and is above the recommendations of PAHO / WHO. The observations during the seasons of the year showed that Spring season (September to December) was the period where there was a higher average of $T$. infestans positive houses detected by the families participating in the study in the three departments of Bolivia. The presence of infected triatomines with Trypanosomatideos in positive houses was $6 \%$ in the study area, still finding active domestic cycles in rural and peri-urban areas and not in urban areas where triatomines with parasites were not reported during the seven years of monitoring.

\section{Conclusions}

Reporting infestation foci by the inhabitants is the simplest and most direct way of participation of the community in entomological surveillance. These strategies should be included in the health policies of the countries, as well as extending and deepening the dialogue between technicians, communities and their local authorities.

\section{Background}

Among communicable diseases, the Chagas disease is the most prevalent in Latin America. This disease results from Trypanosoma cruzi parasite infection, and transmitted by insects of the Triatominae subfamily (Hemiptera: Reduviidae), which are amply extended in communities of the American continent $(1,2)$. 
Triatomine species of epidemiological importance are those which have the ability to colonize houses where they can transmit the T. cruzi parasite to humans. Of the 17 triatomine species currently recognized in Bolivia, only Triatoma infestans meets that definition, being responsible for $80 \%$ of the transmission of vector-borne Chagas disease in endemic areas such as the mesothermal valleys and the "Gran Chaco" area (3).

The disease is associated with rural and peri-urban dwellings in condition of poverty, located at an altitude between 300 and 3,000 meters above sea level, which represents approximately $60 \%$ of the Bolivian territory considered endemic for T. infestans, and involves about four million people at risk (approximately $40 \%$ of the total Bolivian population) (4). This insect completes its life cycle in intra and peridomestic habitats, and vector control strategies are based on the spraying of residual insecticides both inside and outside dwellings (5). The prevention, control and vector entomological surveillance is carried out by the National Chagas Program ( $\mathrm{PNCH}$ ) and one of its objectives is to reduce and maintain the vector infestation inside the houses under $3 \%$ in the national territory (4).

The detection of residual foci in houses, or the triatomines reinfestation of the houses is one of the main challenges of entomological surveillance. Actions aimed at increasing the probability of vector detection and events of re-infestation when the density of vector populations is low, is a priority objective for Chagas control programs (6).

The low sensitivity of entomological search methods inside and outside the houses seems to be one of the more important technical challenges for vector control and it becomes more difficult (and less costeffective) as the control progresses, the foci become scarcer and the density of the colonies decreases. However, denunciation of the presence of vectors by the inhabitants (community participation) tends to be an alternative to the traditional methods of vector search carried out by technicians of the vector control programs trained in the "active search "of the insect (6).

According to $\mathrm{PAHO} / \mathrm{WHO}$ technical recommendations, health systems must be prepared to detect changes and respond to them quickly and efficiently. This response not only requires a good management of entomological and epidemiological information at its different governmental levels, but also to respond with local instruments and interventions for prevention, control and monitoring of proven efficacy and with well-trained personnel in Integrated Vector Management $(7,8,9)$.

The main objective of the study is to evaluate an entomological surveillance strategy with community participation implemented in the Platform Centers for comprehensive healthcare of patients with Chagas disease (CPs) (10), based on the degree of residual vector infestation in houses, the seasonal period of greater capture of triatomines and their rates of natural infection by trypanosomatids in three departments of the endemic area of the mesothermal valleys of Bolivia.

\section{Methods}


The study was conducted between August 2011 and January 2018 in five Platform Centers for comprehensive healthcare of patients with Chagas disease (CPs) in the departments of Cochabamba, Chuquisaca and Tarija (three urban CPs: Cercado Cochabamba, Sucre and Cercado Tarija), and two rural CPs in the department of Cochabamba (Punata and Sacaba)

The intervention area was established within the biogeographic region of the mesothermal valleys of Bolivia with an altitude that varies between 1,950 and 2,600 meters above sea level. This region is listed as an endemic area of T. infestans, the main vector of Chagas disease in Bolivia.

The methodology used to capture triatomines from the CPs was the "entomological surveillance with community participation" recommended by the National Chagas Program, Ministry of Health of Bolivia (PNCH - MS) and implemented in the CPs as part of the "Modelo protocolizado de atención a pacientes con Chagas" (Recorded Model of care for patients with Chagas) (11) (Fig. 1).

The entomological surveillance strategy with community participation was developed as follows: during the first visit of the patient to the $\mathrm{CP}$ where he received comprehensive healthcare for Chagas, the $\mathrm{CP}$ admission staff recorded the patient's data and delivered the material for entomological surveillance (entomological surveillance card and two duly identified capture vessels, a container destined for triatomines captured in the intra-domicile and the second container destined for triatomines captured in the peri-domicile), only after explaining to him/her the central objective of the entomological activity.

The patient, in consultation with the doctor or nurse, received from these professionals the advice and instructions on the use of the entomological surveillance card for the activity of searching for triatomines in their houses (11) (Fig. 2).

On their second scheduled visit or as soon as the patient is followed in the $\mathrm{CP}$, the patient delivers the entomological surveillance material (medical record and triatomine capture vessels) to the nursing staff for their respective verification of the presence or not of triatomines in the patient's house.

In the case that the patient's house checked out positive, the nursing staff assisted the patient in drawing up a basic sketch of the location of the house, and filling in their personal data and in the subsequent case, referral to the Chagas technicians of the Chagas Departmental Program (PDCH) for the verification and confirmation of the presence of triatomines in the community or neighborhood dwelling. The Vector Control actions by PDCH technicians in positive houses were carried out using the chemical spray method with pyrethroids according to PNCH-MS standards and procedures (11).

Subsequently, the vector technician sent the entomological material (triatomines collected by the patients) to the entomological laboratory of the departmental or municipal reference for morphological identification according to the taxonomic keys of Lent and Wygodzinsky (12) and analysis of the trypano/triatominic index (TT index) by microscopic observation of stool drops extracted from triatomines which are mixed with phosphate buffered saline and observed at a magnification of $400 \mathrm{x}$. A 
sample was considered positive each time flagellated parasites were detected during a five-minute examination under the optical microscope.

The consolidation of the information, as per the reception of triatomines, the report of the TT Index, the chemical spraying actions in the positive dwellings with triatomines and the feedback of these actions to the CPs were carried out by the vector's community technicians and/or Municipal vectorial technicians belonging to $\mathrm{PDCH}$.

\section{Results}

36,221 entomological surveillance cards were distributed in patients who requested care in the CPs of both the urban area of the departments of Cochabamba, Tarija and Chuquisaca (CPs of Cercado Cochabamba, Cercado Tarija and Sucre) and in the rural area of the department of Cochabamba (CPs Punata and Sacaba) between the period of August 2011 and December 2018 (Table 1).

Of the total of 36,221 cards that were delivered in the CPs between the years 2011 to $2018,27,643$ cards were registered by the patients and returned to the CPs, corresponding to a participation in the study of $76 \%$ of houses evaluated. Of this total, 852 positive houses were detected with the presence of triatomines (3.1\%), being the area of influence of CP Cochabamba the one that obtained the highest number of complaints of positive houses with $3.8 \%$ in urban areas and CP Punata with $10 \%$ in rural area.

It was observed that 812 houses had the presence of T. infestans in the area of influence of the five CPs of the three departments. Triatoma sordida species was detected in 39 houses in the area of influence of urban Cochabamba and rural Punata CPs. Triatoma guasayana species was found in one house in the area of influence of the rural Punata CP of the department of Cochabamba (Table 1). Likewise, should be mentioned that in 154 houses of the total evaluated, the presence of other insect species (phytophagous and predators) were collected and reported, demonstrating the will and commitment of the family to participate in the entomological surveillance study (Table 1).

From a total of 852 dwellings positive to the presence of triatomines reported by families in the CPs located in the urban and rural area of three departments of Bolivia, 62 houses (8\%) correspond to reports from the urban area, 241 houses (28\%) to the peri-urban area and 549 houses $(64 \%)$ of the rural area. Comparing the reports in the three CPs of the urban area, a high percentage of those of triatomines in houses of the peri-urban area is observed, $55 \%$ in Cochabamba, $44 \%$ in Tarija and $52 \%$ in urban Sucre.

Reports of positive houses of patients from rural areas were: $32 \%, 34 \%$ and $42 \%$ in Cochabamba, Tarija and Sucre respectively. Positive houses in urban areas of influence of these three $\mathrm{CPs}$, is below $22 \%$ (Table 2).

In the area of influence of the CPs of Punata and rural Sacaba, in the department of Cochabamba, it is observed that there is a greater number of positive houses in Punata when compared to CP Sacaba (315 and 80 positive dwellings for triatomines respectively) (Table 2). 
On the basis to the capture of triatomines in the houses of the patients participating in the study, $66 \%$ of captured triatomines come from the intra-domicile and $41 \%$ from the peri-domicile. The

Trypano/Triatominic Index ( $\mathrm{T} / \mathrm{T})$ show that: in the urban area it is $0.0 \%$, in the peri-urban area it is $2 \%$ and in the rural area it is $4 \%$. The T/T Index of the area of influence of the $5 \mathrm{CPs}$ in the three departments reaches $6 \%$ (Table 2).

Comparing the average of the positive houses to the presence of triatomines (study period from 2011 to 2018), we observe that both in the areas of influence of the CPs of the urban and rural area, the department of Cochabamba received a higher average of reports throughout the year than those of CPs of Sucre (Chuquisaca) and Tarija. In the same way, comparing the average of positive housing to the presence of triatomines in relation to the seasons, it is in the spring season where a greater number of reports of positive housing for triatomines were reported in the three departments (urban and rural): Urban Cochabamba (15 SD \pm 7.0 ), Urban Tarija (4 SD \pm 0.8 ) Urban Sucre (4 SD \pm 2.0 ), Rural Punata (16 $S D \pm 9.0)$ and Rural Sacaba (6 SD \pm 3.8$)$, compared to the other stations.

\section{Discussion}

Vector control has substantially reduced the incidence of Chagas disease in Latin America. However, the presence of residual foci and triatomines reinfestation in houses persists, suggesting that entomological surveillance should play a crucial role in the long term (6).

At the beginning of the year 2.000, the endemic area of Bolivia had a $55 \%$ infestation rate of houses by $\mathrm{T}$. infestans. Given this situation, the PNCH with a loan from the Inter-American Development Bank (IDB) and technical support from PAHO / WHO, developed actions of Vector control in a sustained manner accompanied by entomological evaluations with the methodology Hour/Man/House. By 2008, at the conclusion of these continuous and contiguous vector control activities, the impact of the actions reduced the infestation of $\mathrm{T}$. infestans in houses to less than $3 \%$ in the entire endemic area (4).

The low sensitivity of the Time/Man/House $(T / M / H)$ method in the entomological search in a situation of low infestation and low density of vector colonies, began to be a technical problem of relevance (6). The need to detect residual foci or events of re-infestation of houses by triatomines, was undoubtedly one of the main challenges in the transition from a vector control and monitoring model from vertical to a horizontal structure and participatory model.

The sensitivity of vector detection methods is generally unsatisfactory, however, the denunciation of the presence of vectors by the inhabitants, which we call "community participation" method (PC) is clearly superior to the other methods, including active search method (BA) by trained institutional staff and the so-called "sensing devices" $(5,6)$.

There are many existing evidences that corroborate this statement. Among them, we can highlight the works of Garcia-Zapata et al, (13) in Brazil, in which the detection of vectors was between 10 and 16 times more likely using "participatory" strategies than those when the program agents visited the houses; 
de Gurtler et al, (14) in Argentina, where after four years of follow-up (1993-1996) in 98 houses, the chances of detecting $T$. infestans within the houses were seven times higher with PC than with BA; from Feliciangeli et al, (15) in Venezuela, which showed a PC effectiveness much higher than that of BA (with or without repellent/irritant substances): the chances of detection were more than 20 times higher with the first method.

In a period of two years (2.007-2.009), the $\mathrm{PNCH}$ in Bolivia evaluating the sensitivity of the method with community participation (CP) compared to the $\mathrm{T} / \mathrm{M} / \mathrm{H}$, obtained similar results to those described in other countries, which led to design the entomological surveillance card with community participation, an instrument proposed for the present study (Fig. 2).

Between 2.011 and 2.018, 36,221 entomological surveillance cards were distributed in patients who requested care in five CPs in both the urban and rural areas of the departments of Cochabamba, Tarija and Chuquisaca. The data obtained from participation $27,643(76 \%)$ demonstrate a high commitment of patients and their families to actively participate in the search for the vector in the house. One of the relevant factors for this high participation is due to the motivation that the health personnel of the CPs (doctors and nurses) stimulated in the patients as part of the model of integral healthcare for the patient with Chagas disease (10). Similar response was evidenced by Urquiola (16) when a "motivational training" was implemented in a rural community, prior to an entomological evaluation intervention with PC, with active support from its community leaders, compared to another community that did not receive motivational training. The results show a participation in monitoring with PC of $60 \%$ compared to $1 \%$ in the community that did not receive the motivational training respectively.

According to Abad et al (6), it is suggested that stakeholder participation at all stages of the process, from planning to final evaluation, would probably improve PC-based strategies. Several authors suggest as well that a component of education and communication adapted to the socio-cultural environment of the community is obviously necessary to stimulate participation and notification $(17,18,19)$

The average vector infestation in the five CPs reached 3.1\% (852 positive dwellings of a sample of 27,643 dwellings), according to PNCH data in 2018 (unpublished PNCH information), in Bolivia the vector infestation reaches an average of $1.4 \%$.

The data found in the study confirm that the global vector infestation has remained below $3 \%$ for more than a decade in the entire endemic area of the mesothermal valleys of Bolivia, where the presence of the T. infestans species predominates. However, it should be noted that in practice, failures in the detection of vectors are inevitable, particularly when the density of the insect population is low (20), which would lead to an underestimation of the entomological indicators and consequences in the decision making of the operators of the Chagas problem (21).

According to the data obtained in urban and rural areas, the CPs Cercado and Punata in the department of Cochabamba are the ones that report a greater number of positive homes ( $3.8 \%$ and $10 \%$ respectively), when compared to the other CPs of Chuquisaca and Tarija (Table 1). 
In the same way, the data in the three departments show a concentration of positive houses to the presence of the vector in the rural and peri-urban areas when compared to the urban area of the capital cities. This situation is more noticeable and accentuated in the peri-urban belt of the city of Cochabamba, possibly due to several factors among which we can highlight: the ideal environmental conditions for the proliferation of the $T$. infestans species $(22,23)$, human settlements in a situation of poverty established to the east, south and west of the peri-urban belt of the city, partly due to a country-city migration phenomenon since the 1980s (24), and the historical presence of wild foci of T. infestans near the periurban areas where families permanently report the presence of the vector $(22,25,26)$ (Table 2$)$.

The data show that the capture of triatomines in the intra-domicile is greater when compared to the capture in the peri-domicile ( $66 \%$ and $41 \%$ respectively). The PC method, in addition to being more sensitive in detecting triatomine colonies at low densities, also demonstrates a greater capture sensitivity in the intra-domicile than in the peri-domicile, probably because capture spans anywhere from three to five days and also because triatomines.

have nocturnal habits and can be more noticeable by family members when they leave their hiding places for feeding in people's bedrooms (Table 2).

The presence of triatomines infected with Trypanosomatideos in the houses that checked positive, is $6 \%$ in the study area, still finding active domestic cycles in rural and peri-urban areas and not in urban areas where triatomines with parasites were not reported during the seven years of monitoring. According to historical information of the rural area of Cotapachi, Quillacollo in the department of Cochabamba, the Tripano/Triatominic ( $\mathrm{T} / \mathrm{T}$ ) Index of $\mathrm{T}$. infestans captured at house as in triatomines captured in wild areas was $67.4 \%$ and $60 \%$ respectively (23). This information reinforces the need to permanently maintain entomological surveillance in houses near natural areas of wild foci of T. infestans, in order to prevent reinfestation of triatomine dwellings infected with $\mathrm{T}$. cruzi.

Note that the method used to detect the parasite in the vector insect (observation under an optical microscope), is not very sensitive compared to triatomine nucleic acid's detection by amplification based on the Polymerase Chain Reaction methods (PCR). However, PCR methods are not widely available, and its application is limited. In the context of our study, the method used to detect triatomines by the departmental and municipal entomological laboratories in the study area was the direct observation of the parasites through optical microscope.

The observations during the seasons of the year, show that in the spring season (September to December) was the period where there was a higher average of T. infestans positive houses detected by the families participating in the study in the three departments of Bolivia. Similar information was also observed at wild-spot capture sites of Andean T. infestans in the Cotapachi Cochabamba area, where the densities of T. infestans were highest during the hot season (September to January) (26). These findings could probably be related to the biology of the insect vector itself. 


\section{Conclusions}

In rural and peri-urban Punata, in the Department of Cochabamba, the rate of infestation of homes by triatomines exceeds the national average and is above the recommendations of PAHO / WHO.

The presence of triatomines infected with Trypanosomatideos in the houses that checked positive, is $6 \%$ in the study area, still finding active domestic cycles in rural and peri-urban areas and not in urban areas where triatomines with parasites were not reported during the seven years of monitoring.

The observations during the seasons of the year, show that in the spring season (September to December) was the period where there was a higher average of T. infestans positive houses detected by the families participating in the study in the three departments of Bolivia.

The denunciation of infestation foci by the inhabitants is the simplest and most direct way of participation of the community in entomological watch. These strategies should be included in the health policies of the countries, as well as extending and deepening the dialogue between technicians, communities and their local authorities.

\section{Declarations}

\section{Acknowledgments}

Our thanks to the Special Program for Research and Training in Tropical Diseases (TDR, 2007), PAHO / WHO and the Agencia Española de Cooperación Internacional para el Desarrollo (AECID).

\section{Funding}

This work received support from the Agencia Española de Cooperación Internacional para el Desarrollo (AECID; grant 14-COI-558).

\section{Consent for publication}

All authors of this manuscript, declare that we have seen and approved the submitted version and give consent for publication.

\section{Ethics approval}

CEADES Ethics Committee

\section{Data Availability}

Data are available from the Chagas Platform database, under CEADES Ethics Committee for researchers who meet the criteria for access to confidential data.

\section{Competing Interests}


The authors declare that they have no competing interests.

\section{Author contributions}

Study design: MRC. Data analysis: MRC, M-JP, JG, FT. Collection and analysis of field data: JP, HMA, MYEC, GSU, JS, MC, WG, LOD, IGM, DN, MRC. Wrote the manuscript: MRC, M-JP, JG, FT. All authors read and approved the final version of the manuscript.

\section{References}

1. World Health Organization (2002) Control of Chagas Disease. (WHO Technical Report Series 905).

2. BID/OPS/IDRC/CNZ (2010) Programa Regional para el Control de la Enfermedad de Chagas en América Latina. Lineamientos y recomendaciones técnicas y de política pública para la enfermedad de Chagas. Ed. BID, Montevideo, Uruguay. 80 p.

3. Cortez MR, Avalos M, Gorla D. (2007) Distribución biogeográfica de los triatominos en Bolivia: Discriminación de la distribución de las especies en relación a variables ambientales. In: Ministerio de Salud y Deportes, Programa Nacional de Chagas. La Paz: Triatominos de Bolivia y la enfermedad de Chagas. 74-134 p.

4. Programa Nacional de Control de Chagas PNCCH (2008) Informe Anual de Actividades 2008. Ministerio de Salud Bolivia, $24 \mathrm{p}$.

5. BID/OPS/IDRC/CNZ (2010) Programa Regional para el Control de la Enfermedad de Chagas en América Latina. Iniciativa de Bienes Públicos Regionales. Ed. BID. Montevideo Uruguay. 242 p.

6. Abad-Franch F, Vega MC, Rolo'n MS, Santos WS, Rojas de Arias A (2011) Community Participation in Chagas Disease Vector Surveillance: Systematic Review. PLoSNegl Trop Dis 5(6). e1207. doi:10.1371/ journal. pntd. 0001207.

7. World Health Organization (2017) Global Vector Control Response. Geneva: WHO. Available from: http://www.who.int/malaria/areas/vector_control/Draft-WHO-GVCR-2017-2030-esp.pdf.

8. OPS/OMS (2016) Plan de acción para la eliminación de las enfermedades infecciosas desatendidas y las medidas posteriores a la eliminación 2016-2022. 55th Directing Council, 68 th Session of the Regional Committee of WHO for the Americas; Sep 26-30; Washington, DC.: PAHO. Available from: https://www.paho.org/hq/dmdocuments/2016/CD55-15-s.pdf

9. OPS/OMS (2018) Enfermedad de Chagas en las Américas: una revisión de la situación actual de salud pública y su visión para el futuro. Informe: Conclusiones y Recomendaciones. Washington D.C. Available from: https://www.paho.org/hq/index.php? option=com_content\&view=article\&id=14399:enfermedad-de-chagas-en-las-americas-una-revisionde-la-situacion-actual-de-salud-publica-y-su-vision-para-el-futuro\&ltemid=72315\&lang=es

10. Pinazo MJ, Pinto J, Ortiz L, Sánchez J, García W, Saravia R, Cortez MR, Moriana S, Grau E, Lozano D, Gascon J, Torrico F. A strategy for scaling up access to comprehensive care in adults with Chagas 
disease in endemic countries: The Bolivian Chagas Platform. PLoS Negl Trop Dis. 2017 Aug 18;11(8): e0005770. doi: 10.1371/journal.pntd.0005770.

11. Cortez MR (2017) La Red de Vigilancia Entomológica. Implementación de la red de vigilancia entomológica con participación comunitaria a partir del sistema de salud (Centros de Salud) a nivel nacional. In: Carpeta Chagas. Manuales y Guías de procedimiento. Edit CEADES/ISGlobal. Cochabamba, Bolivia.: 109 p.

12. Lent $H$, Wygodzinsky $P$ (1979) Revision of the Triatominae (Hemiptera, Reduviidae), and their Significance as Vectors of Chagas Disease. Bull Am Mus Nat Hist 163:123-520 pp.

13. Garcia-Zapata MT, Marsden PD et al. (1988) Epidemiological vigilance with community participation in the control of the vectors of Chagas' disease in Goias, Central Brazil. Rev Argent Microbiol 20 (Supl.1): 106-17 pp.

14. Gürtler RE, Cecere MC, Canale DM, Castañera MB, Chuit R, et al. (1999) Monitoring house reinfestation by vectors of Chagas disease: a comparative trial of detection methods during a fouryear follow-up. Acta Trop 72(2): 213-234 pp.

15. Feliciangeli MD, Hernandez M, et al. (2007) Comparación de métodos de captura intradomestica de triatominos vectores de la enfermedad de Chagas en Venezuela. Bol Dir Malar Salud Amb 47(1): 103-17 p.

16. Urquiola RC (2018) Eficacia de una capacitación motivacional en la transmisión vectorial en Chagas, previa a la evaluación entomológica con participación comunitaria, en dos comunidades del municipio de Punata abril a junio del 2018. Tesis, Univ. Mayor de San Simón, Fac. Medicina, Pos Grado en Medicina Tropical, Bolivia, 55 p.

17. Dias JCP (2000) Vigilância epidemiológica em doença de Chagas. Cad Saúde Pública 16(Suppl.2): 43-59 p.

18. Lima VLC, Yaguchi MK, Alves ZCPVT (1990) Aspectos da atividade de "notificação de barbeiros" pela população no controle de Panstrongy/us megistus em 12 municípios da região Nordeste do estado de São Paulo, Brasil, 1974 a 1983. Ver. Saúde Pública 24(6): 497-505 p.

19. Falavigna-Guilherme AL, Costa AL, Batista O, Pavanelli GC, Araújo SM (2002) Atividades educativas para o controle de triatomíneos em área de vigilância epidemiológica do Estado do Paraná, Brasil. Cad Saúde Publica 18(6): 1543-1550 p.

20. Schofield CJ (1978) A comparison of sampling techniques for domestic populations of Triatominae. Trans R Soc Trop Med Hyg 72(5): 449-455 pp.

21. WHO (2002) Control of Chagas Disease: Second Report of the WHO Expert Committee. WHO Tech Rep Ser 905: i-vi, 1-109 pp.

22. Noireau F, Cortez, MR, Monteiro FA, Jansen AM, Torrico F (2005) Can wild Triatoma infestans foci in Bolivia Jeopardize Chagas Disease Control Efforts? Trends in Parasitology, 21 (1), 7-10 pp.

23. Cortez MR, Pinho AP, Cuervo P, Alfaro F, et al. (2006) Trypanosoma cruzi (KinetoplastidaTrypanosomatidae): Ecology of the transmission cycle in the wild environment of the Andean valley of Cochabamba, Bolivia. Experimental Parasitology, 114, 305-313 pp. 
24. Mariscal CB, et al. (2011) Migración rural en Bolivia: El impacto del cambio climático, la crisis económica y las políticas estatales. GIZ. 48 p.

25. Torrico RA, (1946) Hallazgo de Eratyrus mucronatus, infestación natural de "vinchucas" de cerro y Eutriatoma sordida en Cochabamba. An. Lab. Central Cochabamba 1, 19-23 p.

26. Cortez MR, Emperaire L, Pinacelli RV, Gurtler R, et al. (2007) Silvatic Triatoma infestans(Reduviidae, Triatominae) in the Andean valleys of Bolivia. Acta Tropica 102, 47-54 pp.

\section{Tables \& Graphs}

Due to technical limitations, Tables 1-2 and Graph 1 are available as Supplementary Files.

\section{Figures}

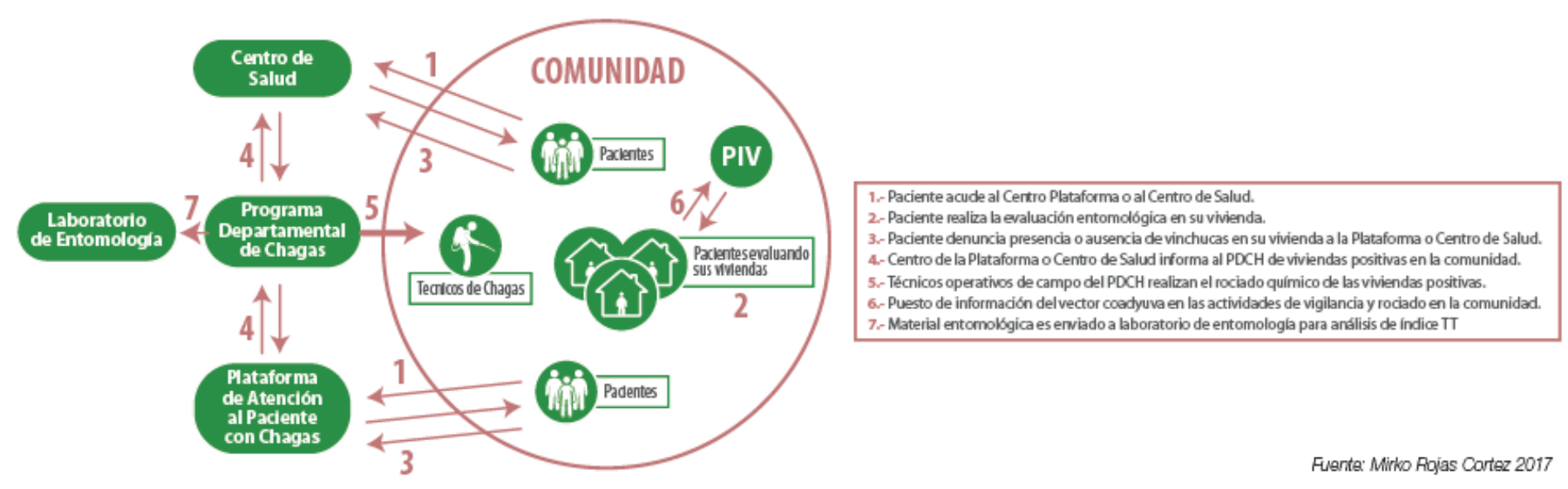

\section{Figure 1}

Scheme of the Entomological Surveillance Network with community participation from Health Centers of the Health System and Centers of Comprehensive Care Centers for patients with Chagas disease (CPs)
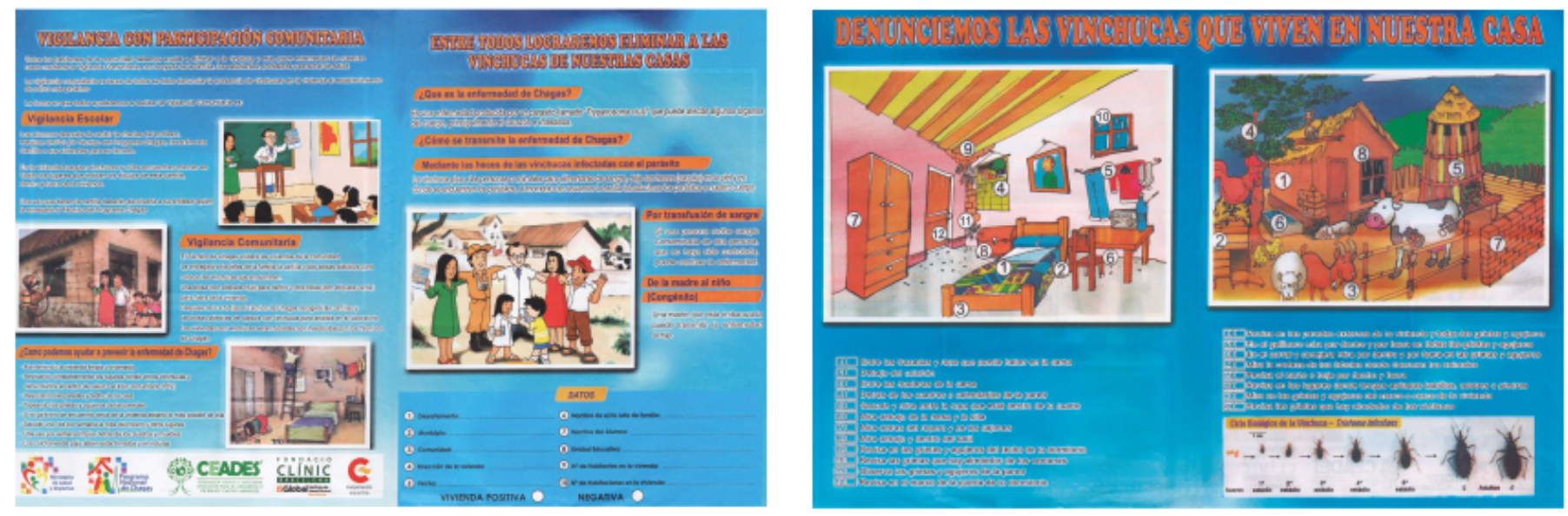

Figure 2 
Design of the primer for entomological surveillance with community participation in the endemic area of Triatoma infestans and triatomines that colonize houses

\section{Supplementary Files}

This is a list of supplementary files associated with this preprint. Click to download.

- Tablesandgraph.docx 